\title{
Excess of cancer in Swedish chimney sweeps
}

\author{
P GUSTAVSSON, ${ }^{12}$ ANNIKA GUSTAVSSON, ${ }^{1}$ C HOGSTEDT ${ }^{12}$ \\ From the Division of Occupational Medicine, ${ }^{1}$ National Institute of Occupational Health, S-171 84 Solna, and \\ the Department of Occupational Medicine, ${ }^{2}$ Karolinska Hospital, S-104 01 Stockholm, Sweden
}

ABSTRACT The incidence of cancer was investigated among 5266 Swedish chimney sweeps employed for any period between 1918 and 1980. An analysis of the mortality has been reported earlier and showed an increased number of deaths from coronary heart disease, respiratory diseases, and lung, oesophageal, and liver cancer. Excess risks for cancer of the lung and oesophagus were confirmed in this analysis. Among the lung cancers, both squamous cell carcinoma and oatcell/undifferentiated carcinoma were in excess. In addition, a more than doubled risk for bladder cancer ( 23 observed $v 9.8$ expected cases) and an increase of malignancies of the haematopoietic system was found. There were, however, no cases of scrotal cancer, the classic occupational hazard among chimney sweeps. Chimney sweeps are exposed to polycyclic aromatic hydrocarbons generated by the combustion of organic material (coal, wood, coke, and oil). They are also exposed to cancerogenic metals (arsenic, nickel, and chromium). These results support the need for improved working conditions.

The working environment of chimney sweeps is contaminated with soot and smoke, generated by the burning of wood, coal, coke, or oil. The soot and smoke contain several carcinogenic compounds, such as polycyclic aromatic hydrocarbons (PAH), arsenic, chromium, and nickel. Furthermore, exposure to asbestos, sulphur dioxide, and organic solvents may occur.'

It has been known since the eighteenth century that chimney sweeps may contract cancer of the scrotum ${ }^{2}$ and this was the first identified occupational cancer. An investigation of the cause specific mortality among Swedish chimney sweeps with a long history of employment showed an excess of cancers of the lung, oesophagus, and liver, and of leukaemia. ${ }^{3}$ Some of these excesses were supported in a study of Danish chimney sweeps which also showed an increased risk of ischaemic heart disease. ${ }^{45}$ An investigation of Yugoslavian chimney sweeps showed a high mortality from cancer of the lung and larynx. ${ }^{6}$ An extension of the Swedish study confirmed the earlier findings of increased cancer mortality and ischaemic heart disease. $^{7}$

In the present study the incidence of cancer among Swedish chimney sweeps was investigated, focusing the interest primarily on less fatal forms of cancer that might not have been covered by the mortality analysis and on histological tumour types and on confirmation of the mortality results.

Accepted 21 September 1987

\section{Material and methods}

The study included all male, trade union organised chimney sweeps in Sweden, employed any time between 1918 (when the union was established) and 1980. The records of the union were used as source material.

A total of 5542 chimney sweeps were identified from the register. About $95 \%$ of Swedish chimney sweeps are union organised and thus the cohort comprises nearly all Swedish chimney sweeps. Follow up was obtained by matching with a computerised register of the living population at the National Insurance Authority. Those not found in this register were traced through death and burial books of the clerical parishes.

Up to 1958 when the study period started 198 individuals had died. By 1981 another 605 cohort members had died, 39 had emigrated, seven were officially registered as missing, and 32 were lost to follow up. Vital outcome was traced for $98.6 \%$ of the individuals in the cohort. Those who had emigrated, were missing, or not traced were excluded from the study. Table 1 shows the distribution of person-years for the remaining 5266 cohort members.

Cases of cancer were identified from the Swedish National Cancer Registry. Information on cancer sites and results of histological or cytological analyses were obtained from the register. All tumours registered from 1958 (when the register started) to 1981 were included in the study. 
Table 1 Person-years by exposure time (years) and latency (years)

\begin{tabular}{lrrlll}
\hline \multirow{8}{*}{ Latency } & \multicolumn{2}{l}{ Exposure time } \\
\cline { 2 - 6 } & $0-9$ & $10-19$ & $20-29$ & $\geqslant 30$ & Total \\
\hline $0-9$ & 28164 & - & - & - & 28164 \\
$10-19$ & 12045 & 13812 & - & - & 25857 \\
$20-29$ & 6289 & 6004 & 5114 & - & 17407 \\
$\geqslant 30$ & 2434 & 5388 & 3721 & 4958 & 16501 \\
Total & 48932 & 25204 & 8834 & 4958 & 87929 \\
\hline
\end{tabular}

Expected numbers of cancers were computed from national cancer rates ${ }^{8}$ according to the person-years method. The distribution of person-years over calendar year and five year age class was computed. The number of person-years in each cell was multiplied with the cancer rate in the corresponding cell of the national statistics, and the number of expected cases so obtained were added. The summary risk measure obtained is the standardised morbidity ratio.

A $95 \%$ confidence interval for the SMR was calculated with an exact method, based on the Poisson distribution.' Test for trend in the SMR was performed according to a method described by Breslow et al. ${ }^{10}$

Background rates for histological types of lung tumours were obtained from the cancer registry and the classification of tumour types used in the register was retained in this study. Thus adenocarcinomas and squamous cell carcinomas have separate codes, whereas small cell carcinomas (oat cell cancers) are grouped together with undifferentiated carcinomas.

The exposure to different compounds in the soot and smoke varies between different types of work, depending on the type of fuel used and if the chimneys are entered by the sweep during the operation.' A quantitative characterisation of the exposure was not possible on an individual level, and the number of years employed was used as a surrogate of the dose in the exposure-response analysis. Some chimney sweeps become a master, leave the union, and start their own enterprise. Although the masters may take part in the work in small districts most of their work is administrative, and work as a master was not considered when exposure response relations were analysed. The duration of employment as chimney sweep and chimney sweep master is presented in table 2 .

Table 2 Duration of employment as chimney sweep and master

\begin{tabular}{llll}
\hline \multirow{2}{*}{ Type of work } & \multicolumn{3}{l}{ Duration of employment (years) } \\
\cline { 2 - 4 } & Mean & $S D$ & Median \\
\hline Chimney sweep & $12 \cdot 0$ & $12 \cdot 2$ & $9 \cdot 0$ \\
Chimney sweep and master & $14 \cdot 1$ & $14 \cdot 2$ & $9 \cdot 0$ \\
\hline
\end{tabular}

Table 3 Incidence of cancer among Swedish chimney sweeps 1958-81. (International Classification of Disease, 7th ed)

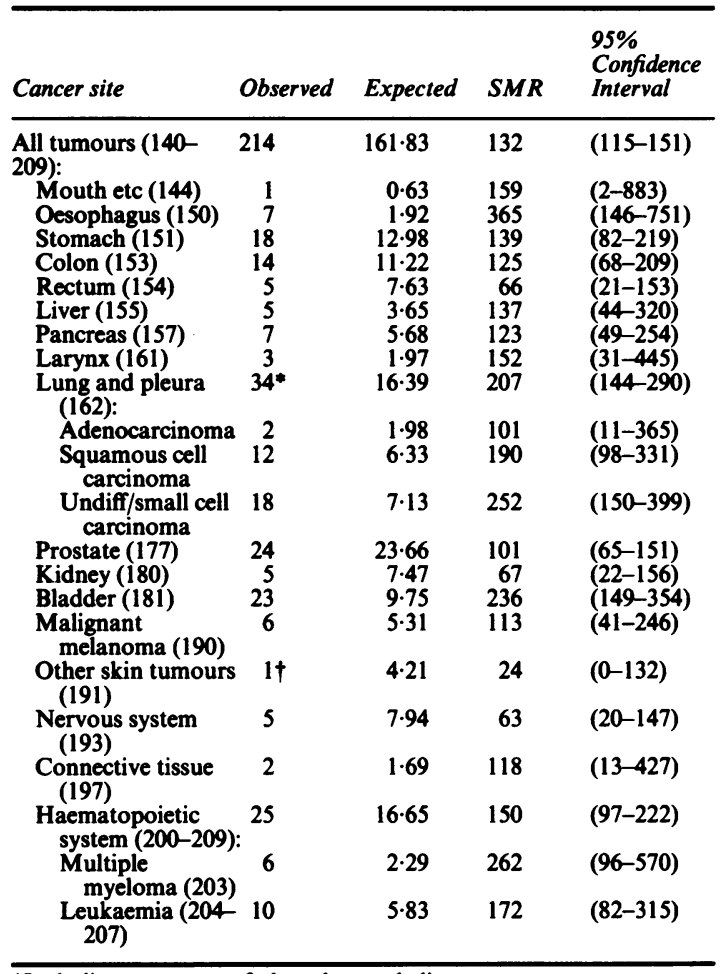

*Including two cases of pleural mesothelioma.

†No cases of scrotal cancer were found.

\section{Results}

There was a significant excess of cancers of the lung, oesophagus, and bladder and the total incidence of cancer was also significantly raised (table 3 ). There was a nearly significant increase of haematopoietic malignancies, relating both to leukaemia and multiple myeloma. The excess of lung cancers was caused by an excess of squamous cell and undifferentiated/small cell carcinomas. Two cases were registered as pleural mesotheliomas.

There were 23 cases of bladder cancer compared with 9.75 expected. Of these, 19 were histologically verified as urothelial cancer, two were cancer in situ, one was a leiomyosarcoma, and in one case information on histological type was missing.

Table 4 gives the incidence of cancer during different periods of follow up. The observed and expected numbers of total cancers correspond well during the first three decades of follow up but were increased during follow up more than 30 years from the beginning of exposure. The excess risk for cancer of the oesophagus, stomach, lung, and bladder depended 
Table 4 Observed and expected incidence (Obs/Exp (SMR)) of selected types of tumour by follow up period

\begin{tabular}{|c|c|c|c|c|c|c|}
\hline \multirow[b]{2}{*}{ Tumour site } & \multicolumn{6}{|c|}{ Period of follow up (years) } \\
\hline & $0-9$ & $10-19$ & $20-29$ & $30-39$ & $40-49$ & $\geqslant 50$ \\
\hline $\begin{array}{l}\text { All tumours } \\
\text { Oesophagus } \\
\text { Stomach } \\
\text { Lung } \\
\text { Bladder } \\
\text { Haematopoietic system }\end{array}$ & $\begin{array}{l}8 / 7 \cdot 40(108) \\
0 / 0 \cdot 01(-) \\
0 / 0 \cdot 12(-) \\
0 / 0 \cdot 12(-) \\
0 / 0 \cdot 19(-) \\
4 / 1 \cdot 99(201)\end{array}$ & $\begin{array}{l}11 / 12.83(86) \\
0 / 0.03(-) \\
0 / 0.51(-) \\
0 / 0.50(-) \\
0 / 0.51(-) \\
4 / 2.30(174)\end{array}$ & $\begin{array}{l}23 / 21 \cdot 94(105) \\
1 / 0 \cdot 17(588) \\
0 / 1 \cdot 44(-) \\
2 / 2 \cdot 0(100) \\
2 / 1 \cdot 27(157) \\
5 / 2 \cdot 76(181)\end{array}$ & $\begin{array}{l}48 / 32 \cdot 04(149) \\
1 / 0 \cdot 45(222) \\
6 / 2 \cdot 49(241) \\
9 / 4 \cdot 06(222) \\
7 / 2 \cdot 25(311) \\
3 / 3 \cdot 12(96)\end{array}$ & $\begin{array}{l}45 / 33 \cdot 37(134) \\
4 / 0 \cdot 53(755) \\
5 / 3 \cdot 11(161) \\
8 / 4 \cdot 36(183) \\
4 / 2 \cdot 24(179) \\
4 / 2 \cdot 73(146)\end{array}$ & $\begin{array}{l}79 / 54 \cdot 25(146) \\
1 / 0 \cdot 73(137) \\
7 / 5 \cdot 31(132) \\
15 / 5 \cdot 35(280) \\
10 / 3 \cdot 29(304) \\
5 / 3 \cdot 75(133)\end{array}$ \\
\hline
\end{tabular}

Table 5 Incidence of cancer by duration of employment calculated with a latency requirement of 30 years

\begin{tabular}{|c|c|c|c|c|c|c|c|c|c|c|c|c|}
\hline \multirow[b]{3}{*}{ Cancer site } & \multicolumn{12}{|c|}{ Employment time (years) } \\
\hline & \multicolumn{3}{|c|}{$0-9$} & \multicolumn{3}{|c|}{$10-19$} & \multicolumn{3}{|c|}{$20-29$} & \multicolumn{3}{|c|}{$\geqslant 30$} \\
\hline & $o$ & $E$ & $S M R$ & $o$ & $E$ & $S M R$ & $o$ & $E$ & $S M R$ & $O$ & $E$ & $S M R$ \\
\hline $\begin{array}{l}\text { All tumours } \\
\text { Oesophagus } \\
\text { Stomach } \\
\text { Lung } \\
\text { Bladder }\end{array}$ & $\begin{array}{r}16 \\
1 \\
2 \\
2 \\
2\end{array}$ & $\begin{array}{r}11.31 \\
0.17 \\
0.81 \\
1.44 \\
0.81\end{array}$ & $\begin{array}{l}141 \\
588 \\
247 \\
139 \\
247\end{array}$ & $\begin{array}{r}40 \\
1 \\
5 \\
6 \\
7\end{array}$ & \begin{tabular}{r|}
29.76 \\
0.43 \\
2.38 \\
3.71 \\
2.05
\end{tabular} & $\begin{array}{l}134 \\
233 \\
210 \\
162 \\
341\end{array}$ & $\begin{array}{r}40 \\
1 \\
4 \\
12 \\
5\end{array}$ & $\begin{array}{r}29.52 \\
0.42 \\
2.67 \\
3.49 \\
1.93\end{array}$ & $\begin{array}{l}136 \\
238 \\
150 \\
344 \\
259\end{array}$ & $\begin{array}{r}77 \\
3 \\
7 \\
12 \\
7\end{array}$ & $\begin{array}{r}49.07 \\
0.69 \\
5.05 \\
5.13 \\
2.99\end{array}$ & $\begin{array}{l}155 \\
435 \\
139 \\
234 \\
234\end{array}$ \\
\hline
\end{tabular}

mainly on an excess during follow up for more than 30 years from start of exposure. The number of expected cases during the first 30 years, however, was small and an excess risk cannot be excluded for this period. The pattern is different for cancers of the haematopoietic system, with an excess appearing during earlier decades of follow up. The median latency time (time from start of exposure to diagnosis) was calculated for the different tumour types; it was 43 years for oesophageal cancer, 47.5 years for lung cancer, 43.5 years for bladder cancer, 27.5 years for cancers of the haematopoietic system, and 42 years for all types of tumours.

Exposure response relations were investigated using number of years employed as a surrogate of the cumulated dose (table 5). A general latency requirement of 30 years was used. Cancers of the haematopoietic system seem to have a shorter latency and were not included in this analysis. The SMR for lung cancer seems to increase with number of years employed but the trend was not statistically significant. For the other types of cancer the SMR fluctuated due to small numbers. There was no exposure response trend for total number of cancers.

\section{Discussion}

The main new result of this study is the finding of a highly increased incidence of bladder cancer among chimney sweeps. The carcinogenic properties of several of the PAH compounds that occur in soot and smoke are well documented, in experimental ${ }^{11}$ and in epidemiological studies. ${ }^{12}$ The epidemiological evidence for PAH as a bladder carcinogen is accumulating; risk excesses for this disease have been found among tobacco smokers, ${ }^{13}$ aluminium smelter workers ${ }^{14}$ and gas production workers. ${ }^{15}$ The current finding of an increased risk of bladder cancer among chimney sweeps adds further evidence for such an association.

Benzo(a)pyrene (B(a)P) has been extensively studied experimentally as a model substance for PAHs in general. $\mathbf{B}(\mathrm{a}) \mathbf{P}$ is readily absorbed through cellular membranes and is quickly distributed in the body after intratracheal instillation, inhalation, injection, or cutaneous application in experimental animals. " For the chimney sweeps, the PAH probably enters the body through the respiratory system and then enters the circulatory system either through direct resorption in the bronchi, or is expectorated, swallowed, and absorbed through the gastric and intestinal mucosa. Experimental data indicate that both routes of uptake may be relevant. " The excess of oesophageal cancer could be explained by a direct action of the PAH on the oesophageal mucosa during the passage to the stomach after swallowing. The main route for excretion of $\mathrm{B}(\mathbf{A}) \mathbf{P}$ and its metabolites is in the bile and faeces while $4-12 \%$ is excreted in the urine of experimental animals. ${ }^{16}$

No cases of scrotal cancer were found and the incidence of skin cancer in general was lower than expected. This might seem surprising since PAH induces skin cancer in laboratory animals and this cancer is the classic occupational cancer hazard of chimney sweeps. The lack of excess risk for skin cancer might, however, result from the Swedish chimney sweeps' right to take a bath at the end of the working day, regulated in the contract of employment, and 
other individual hygienic improvements.

Exposure to asbestos of a rather low and intermittent character occurs for chimney sweep ${ }^{17}$ and the two cases of mesothelioma might be attributable to this exposure.

The excesses of leukaemia and haematopoietic malignancies in general were of borderline statistical significance. There is no earlier epidemiological evidence for PAH as a leukaemogen but there is some experimental evidence; 7,12-dimethylbenz(a)anthracene and 7,8,12-trimethylbenz(a)anthracene induces leukaemia in rats. ${ }^{18}$ The current findings indicate that PAH might be a risk factor for leukaemia in man but the association should be confirmed in other studies before it is accepted. Other substances in the smoke and soot may also have contributed to the excess.

The subdivision of cases of lung cancer by histological types showed an excess of both undifferentiated/small cell carcinomas and squamous cell carcinomas. The SMR for adenocarcinomas was near 100 but this should not be interpreted as evidence against an increased risk also for adenocarcinomas because of the small number of cases and the wide confidence interval for the SMR. No re-examination of histological specimens was performed but systematic errors in this coding must be considered unlikely. Those random errors that might occur could be expected to influence only the magnitude of the excess risks found.

The analysis of exposure response relations showed a weak correlation between duration of employment and incidence of lung cancer, but for the other tumour forms no such correlation was found. The reason for this lack of correlation might be that duration of exposure is a poor approximation of the actual dose of carcinogens received by each chimney sweep because of the variation in working conditions and the different types of fuels used. In addition, some of those chimney sweeps who have subsequently become masters may have had a significant contribution to their cumulated exposure of carcinogens during this latter period of work. An additional analysis was performed (results not shown), including the number of master-years in the employment time, but no closer correlation between exposure and response was found with this method. Unfortunately, no individual data were available on what type of work had actually been performed during the master period.

The combination of risk increases for lung, oesophageal, and bladder cancer, and ischaemic heart disease raises the question as to whether the chimney sweeps' smoking habits may have contributed to, or even fully account for, the increased risks. The smoking habits among Swedish chimney sweeps were investigated in $1973^{19}$ and, as was shown in an earlier report, ${ }^{7}$ could account for only around a $1 \%$ increase in the rate of lung cancer compared with the national average. ${ }^{20}$ Against this background it seems unlikely that smoking habits have contributed significantly to the other excesses of cancer found.

The incidence of primary liver cancer was not increased whereas the analysis of mortality showed a significant excess of this disease. ${ }^{7}$ Of the nine cases who had died from liver cancer (ICD $8=155$ ), the following had different diagnoses in the cancer registry; two cases were coded as "not indicated as primary" (ICD $7=156$ ), one as stomach cancer, one as a soft tissue sarcoma, and one as a tumour of unknown origin. Coding of underlying causes of death is generally based on clinical observations and postmortem findings and is not subject to later revision after histological analyses to the same extent as are the cancer registry data. In general, the Swedish cancer registry has a high accuracy with regard to completeness and correctness of the recorded information, and the correspondence to the recordings of deaths from cancer in the register of causes of death is generally good. ${ }^{21}$ In this case, however, it seems as if the analysis of mortality included some cases of other tumour forms under the heading "primary liver cancer," and that the apparent excess mortality actually relates to tumour types other than primary liver cancer.

In general, this investigation of the incidence of cancer among chimney sweeps supports the earlier findings of increased cancer mortality in the group. PAH seem to be the main factor underlying the excess of cancers of the lung and bladder, and possibly also the excess of leukaemia. Exposure to other carcinogens in the work environment, such as metals and asbestos, may have contributed to the excess of lung cancer.

Since the latency from start of exposure to development of cancer is long, our findings reflect the outcome of working conditions that were present several decades ago, and the relevance for the chimney sweeps' current occupational environment could be questioned. The working conditions for chimney sweeps have been only marginally improved during recent years, however, due to difficulties in finding appropriate technical solutions for eliminating contaminants in the work environment and our findings support the need for intensified work in this field.

This study was supported by a grant (83-0811) from the Swedish Work Environment Fund.

\section{References}

1 Fehrmann R. Characterization of chimney sweep's occupational environment. Copenhagen: Danish Work Environment Fund, 1982. (In Danish.)

2 Pott P. Chirurgical observations relative to the cataract, the polypus of the nose, the cancer of the scrotum, the different kinds of ruptures, and the mortification of the toes and feet. London: 
Hawes, Clarke and Collins, 1775:7-13.

3 Hogstedt C, Andersson K, Frenning B, Gustavsson A. A cohort study on mortality among long-time employed Swedish chimney sweeps. Scand J Work Environ Health 1982;8 suppl 1:72-8.

4 Hansen E, Olsen J, Tilt B. Cancer and non-cancer mortality of chimney sweeps in Copenhagen. Int J Epidemiol 1982;11:35661 .

5 Hansen E. Mortality from cancer and ischemic heart disease in Danish chimney sweeps: a five-year follow up. Am J Epidemiol 1983;117:160-4.

6 Cadez E. Ergebnisse langjähriger Untersuchungen über den Einfluss von Schadstoffen auf die Gesundheit von Schornsteinfegern. Staub Reinhalt Luft 1983;43:116-7.

7 Gustavsson P, Gustavsson A, Hogstedt C. Excess mortality among Swedish chimney sweeps. Br J Ind Med 1987;44:738-43.

8 National Board of Health and Welfare. Cancer incidence in Sweden. Stockholm: Cancer Registry, 1958-81.

9 Mulder PGH. An exact method for calculating a confidence interval of a poisson parameter. Am J Epidemiol 1983;117:377.

10 Breslow NE, Lubin JH, Marek P, Langholz B. Multiplicative models and cohort analysis. Journal of the American Statistical Society 1983;78:1-12.

11 International Agency for Research on Cancer. Monographs on the evaluation of the carcinogenic risk of chemicals to humans. Vol 32. Polynuclear aromatic compounds. Lyon: IARC. 1983.

12 International Agency for Research on Cancer. Monographs on the evaluation of the carcinogenic risk of chemicals to humans. Vol 34. Polynuclear aromatic compounds. Lyon: IARC, 1984.

13 Morrison AS, Cole P. Urinary tract. In: Schottenfeld S, Fraumeni
JF, eds. Cancer epidemiology and prevention. Philadelphia: Saunders, 1982:925-37.

14 Thériault G, Tremblay C, Cordier S, Gingras S. Bladder cancer in the aluminium industry. Lancet 1984; i:947-50.

15 Doll R, Vessey P, Beasley RWR, et al. Mortality of gasworkers: final report of a prospective study. Br J Ind Med 1972;29:394 406.

16 Kotin P, Falk HL, Busser R. Distribution, retention, and elimination of C14-3,4-benzpyrene after administration to mice and rats. J Natl Cancer Inst 1959;23:541-55.

17 Chang G. Chemical health hazards in chimney sweeping. Stockholm: Research Department, National Board of Occupational Safety and Health, 1980. (Report No 2603/79.) (In Swedish.)

18 Sugiyama T, Venaka H, Veda N, Fukuhara S, Maeda S. Reproducible chromosomal changes of polycyclic hydrocarbon-induced rat leukemia: incidence and chromosome banding pattern. J Natl Cancer Inst 1978;69:153-60.

19 Swensson $\AA$, Swensson A. Chimney sweeps trade union health survey 1972. Stockholm: Research Department, National Board of Occupational Safety and Health, 1974. (Report No AMMM 101/04.) (In Swedish.)

20 Cederlöf $\mathrm{R}$, Friberg $\mathrm{L}$, Hrubec $\mathrm{Z}$, Lorich $\mathrm{U}$. The relationship of smoking and some social covariables to mortality and cancer morbidity. Stockholm: Department of Environmental Hygiene, Karolinska Institute, 1974.

21 Mattsson B. Cancer registration in Sweden. Studies on completeness and validity of incidence and mortality registers. Stockholm: Karolinska Institute, 1984. (Academic dissertation.)

\section{Correspondence and editorials}

The British Journal of Industrial Medicine welcomes correspondence relating to any of the material appearing in the journal. Results from preliminary or small scale studies may also be published in the correspondence column if this seems appropriate. Letters should be not more than 500 words in length and contain a minimum of references. Tables and figures should be kept to an absolute minimum. Letters are accepted on the understanding that they may be subject to editorial revision and shortening.

The journal now also publishes editorials which are normally specially commissioned. The Editor welcomes suggestions regarding suitable topics; those wishing to submit an editorial, however, should do so only after discussion with the Editor. 